\title{
Interpretation of a Manometric Trace of the Upper Esophageal Sphincter
}

TO THE EDITOR: While reporting the complexity behind the interpretation of the manometric trace of the upper esophageal sphincter (UES), Bhatia and Shah ${ }^{1}$ wrote: "It is a technically demanding procedure due to the anatomy of the UES, as is the movement of the sphincter during swallowing."

We agree with the authors that some of the difficulties are due to the movement of the sphincter during swallowing. This is proved by the fact that for example the contraction of the sphincter is still referred to by many different terms, including "closing tone, closing phase, sphincter contraction and post-swallow UES contraction etc."

They nicely showed the limitations of manometry. They reported that "The parameters which are most evaluated are baseline UES pressure, UES relaxation time, nadir pressure during UES relaxation, UES co-ordination with pharyngeal contraction, amplitude of pharyngeal contraction and intrabolus pressure." These are well-established factors associated with motility abnormalities of the UES. ${ }^{2-4}$

So, to ask an old question, how should the UES manometry be interpreted? To give a contribution to the UES motility, we have recently reviewed our experience, and have stressed the fact that scientists are likely to focus only on the co-ordination between the pharynx and the UES and often disregard the co-ordination of the UES with the upper esophageal contraction (called crico-esophageal coordination). ${ }^{5}$ We dissected the manometry of the UES into a two-phase waveform. The first of relaxation is normal when it occurs before the onset of the pharyngeal contraction while the second phase of contraction is normal when the peak of UES contraction precedes the peak of the UE contraction. The correlation between the UES and the upper esophagus has been demonstrated also using different methodologies such as histochemical analysis, ${ }^{6}$ biomechanical markers and electromyographic study. The analysis of the crico-esophageal coordination permitted us to identify abnormalities in several patients suffering from high dysphagia that would have been remained undiagnosed. Crico-esophageal abnormalities have been found in patients with Zenker diverticulum, ${ }^{7}$ tight Nissen ${ }^{8}$ and achalasia of the LES. ${ }^{9}$ A new classification of the pharyngo-esophageal motility disorders was proposed: pharyngeal (pre-sphincteric), sphincteric and esophageal (post-sphincteric) disorders. ${ }^{10}$

To conclude, although we also agree with the authors' final conclusion: "UES manometry is useful in the management of patients with dysphagia," we believe that for a more precise understanding of the UES disorders the study of the crico-esophageal coordination should be added. Further investigative work may be required in the evaluation of the UES.

Marcello Migliore

Department of Surgery, University of Catania, Catania, Italy

1. Bhatia SJ, Shah C. How to perform and interpret upper esophageal sphincter manometry. J Neurogastroenterol Motil 2013;19:99-103.

2. Cook IJ, Kahrilas PJ. AGA technical review on management of oropharyngeal dysphagia. Gastroenterology 1999;116:455-478.

3. Jungheim M, Miller S, Ptok M. [Methodological aspects of high resolution manometry of the pharynx and upper esophageal sphincter.] Laryngorhinootologie 2013;92:158-164. [German]

4. Xiang X, Tu L, Zhang X, Xie X. Hou X. Influence of the catheter diameter on the investigation of the esophageal motility through solid-state high-resolution manometry. Dis Esophagus Published Online First 5 Feb 2013. doi: 10.1111/dote.12029.

5. Migliore M. A dissection of a manometric trace of the upper esophageal sphincter and the crico-esophageal coordination. Ann Ital Chir 2013;84:133-136.

6. Lerut $\mathrm{T}$, Coosemans $\mathrm{W}$, Cuypers $\mathrm{P}$, et al. The pharyngoesophageal segment: cervical myotomy as therapeutic principle for pharyngoesophageal disorders. Dis Esophagus 1996;9:22-32.

7. Migliore M, Payne H, Jeyasingham K. Pathophysiologic basis for operation on Zenker's diverticulum. Ann Thorac Surg 1994;57: 1616-1620; discussion 1620-1621.

8. Migliore M, Deodato G. Clinical features and oesophageal motility in patients with tight fundoplication. Eur J Cardiothorac Surg 1999; 16:266-272. 
9. Migliore M, Arcerito M, Giuliano R, Gangi S, Basile F, Deodato G. Pharyngo-esophageal dysphagia as a clinical presentation of esophageal achalasia. Gastroenterology 2000;118:A408.

10. Migliore M, Payne HR, Jeyasingham K. Pharyngo-oesophageal dysphagia: surgery based on clinical and manometric data. Eur J
Cardiothorac Surg 1996;10:365-371.

Conflicts of interest: None. 